\title{
Errata
}

Epidemiol. Infect. 114 (1995), 20

K. E. OrR, N. F. Lightfoot, P. R. Sisson et AL.

\section{Direct milk excretion of Campylobacter jejuni in a dairy cow causing cases of human enteritis}

Legend for Figure 1 should read: 'Ordination diagram of spectral data of $C$.jejuni isolates. The axes represent the first two canonical discrete functions. The means of triplicate analysis of subcultures of the same isolate have been joined together. 31 and 41 , isolates from unassociated human cases; 25 , isolate from faeces of cow 513.

$$
\text { Epidemiol. Infect. } 114 \text { (1995), 319-44 }
$$

H. R. Babad, D. J. Nokes, N. J. Gay, E. Miller, P. Morgan-Capner AND R. M. ANDERSON

Predicting the impact of measles vaccination in England and Wales: model validation and analysis of policy options

Page 339, Fig. 12. In the figure, open markers should be filled, and vice versa. 